ARTICLE

Received 3 Oct 2016 | Accepted 27 Feb 2017 | Published 25 Apr 2017

\title{
Synthesis of extended polycyclic aromatic hydrocarbons by oxidative tandem spirocyclization and 1,2-aryl migration
}

Xuan Zhang ${ }^{1}$, Zhanqiang Xu1 ${ }^{1}$, Weili $\mathrm{Si}^{1}$, Kazuaki Oniwa ${ }^{1}$, Ming Bao ${ }^{2}$, Yoshinori Yamamoto ${ }^{1,2} \&$ Tienan Jin ${ }^{1,2}$

The extended polycyclic aromatic hydrocarbons (PAHs) have received significant interdisciplinary attention due to their semiconducting applications in diverse organic electronics as well as intriguing structural interests of well-defined graphene segments. Herein, a highly efficient oxidative spirocyclization and 1,2-aryl migration tandem synthetic method for the construction of extended polyaromatic hydrocarbons (PAHs) has been developed. The $\mathrm{CuCl}$-catalyst/ $/ \mathrm{PhCO}_{3}{ }^{\mathrm{t}} \mathrm{Bu}$ or $\mathrm{DDQ}$ oxidation system in the presence of trifluoroacetic acid enables the selective single-electron oxidation to take place preferentially at the more electron-rich alkene moiety of o-biphenylyl-substituted methylenefluorenes, giving rise to the subsequent tandem process. A variety of structurally diverse extended PAHs including functionalized dibenzo[g,p]chrysenes, benzo[f]naphtho[1,2-s]picene, hexabenzo $[a, c, f, j, j, l, o p]$ tetracene, tetrabenzo[ $[a, c, f, m]$ phenanthro[9,10-k]tetraphene, tetrabenzo[a,c,f,k] phenanthro $[9,10-m]$ tetraphene, tetrabenzo $[a, c, f, o]$ phenanthro $[9,10-m]$ picene and $S$-type helicene have been readily synthesized.

\footnotetext{
${ }^{1}$ WPI-Advanced Institute for Materials Research (WPI-AIMR), Tohoku University, Sendai 980-8577, Japan. ${ }^{2}$ State Key Laboratory of Fine Chemicals, Dalian University of Technology, Dalian 116012, China. Correspondence and requests for materials should be addressed to T.J. (email: tjin@m.tohoku.ac.jp).
} 
$\mathrm{T}$ he extended polycyclic aromatic hydrocarbons (PAHs) have received significant interdisciplinary attention due to their semiconducting applications in diverse organic electronics as well as intriguing structural interests of well-defined graphene segments ${ }^{1-8}$. A variety of synthetic methodologies for constructing various $\pi$-extended PAHs have been developed towards achieving high efficiency and novelty ${ }^{5-15}$. Among them, since the seminal advance has been made by Müllen and Spiess et al. towards synthesizing hexa-perihexabenzocoronene ( $p$-HBC) through a highly efficient oxidative intramolecular cyclodehydrogenation (Scholl reaction) of hexaphenylbenzene $e^{16,15}$, the selective oxidative aromatic coupling of unfunctionalized arenes with a net loss of hydrogens has become the most popular, straightforward and atom-economical synthetic strategy of various PAHs involving nanographene and graphene ${ }^{5-9}$. However, this methodology still has some problems such as unpredictable regioselectivities due to the different activity of aromatic $\mathrm{C}-\mathrm{H}$ bonds, electronic property of arenes and stereo factors. In this context, the discovery of novel and expedient aromatization methods towards structurally diverse PAHs with selectivity control and high efficiency is highly desirable.

Recently, we have developed a novel $\mathrm{FeCl}_{3}$-mediated oxidative dehydrogenative spirocyclization of 1,2-di(9H-fluoren-9-ylidene)1,2-diphenylethane for the synthesis of a new class of the dispirolinked $\pi$-system DSFIIF (Fig. 1a $)^{18}$. In this study, the conjugated diene moiety in 1,2-di(9H-fluoren-9-ylidene)-1,2diphenylethane was predicted to be more electron-rich than the fluorenyl and phenyl moieties by the frontier molecular orbital calculation, which suggests that it would easily undergo twofold single-electron oxidation preferentially to form a dication species, followed by the intramolecular Friedel-Crafts reaction to afford the corresponding dispirocycle DSFIIF. In light of this observation, we designed a new olefin substrate 9-(biphenyl-2ylmethylene)-9H-fluorene (BPMF), in which the alkene moiety was calculated to possess relatively higher electron density compared to other moieties (Fig. 1b and Supplementary Fig. 1). Inspired by this observation, we anticipated that if a radical cation forms selectively at the alkene moiety of BPMF by employing appropriate single-electron oxidation systems, the subsequent spirocyclization and 1,2-aryl migration tandem process may take place to give the desired twisted molecule dibenzo[ $g, p]$ chrysene (DBC), which is an intriguing holding block of discotic molecules, fluorescent and charge carrier-transporting materials. Diverse synthetic methods of the DBC derivatives have been reported, such as oxidation of electron-rich bis(biaryl)acetylenes, oxidation of electron-rich tetraarylethylenes, intramolecular aromatic $\mathrm{C}-\mathrm{H} / \mathrm{C}-\mathrm{Br}$ coupling, double Suzuki-Miyaura coupling, and $\mathrm{Pd}$-catalysed coupling of $\mathrm{C}-\mathrm{H}$ bonds of small $\mathrm{PAHs}$ with dimethyldibenzosilole ${ }^{13-15,19-28}$. On the basis of our reaction design, we herein describe a novel dehydrogenative $\mathrm{PAH}$ synthetic methodology based on the oxidative spirocyclization and 1,2-aryl migration tandem process. A variety of extended PAHs involving functionalized DBCs, hexabenzotetracene, tetrabenzophenanthrotetraphene, tetrabenzophenanthropicene and helicene derivatives have been readily synthesized in good to high yields without prefunctionalization of aromatic rings.

a Oxidative spirocyclization for $\pi$-conjugated dispirocycles: our previous study

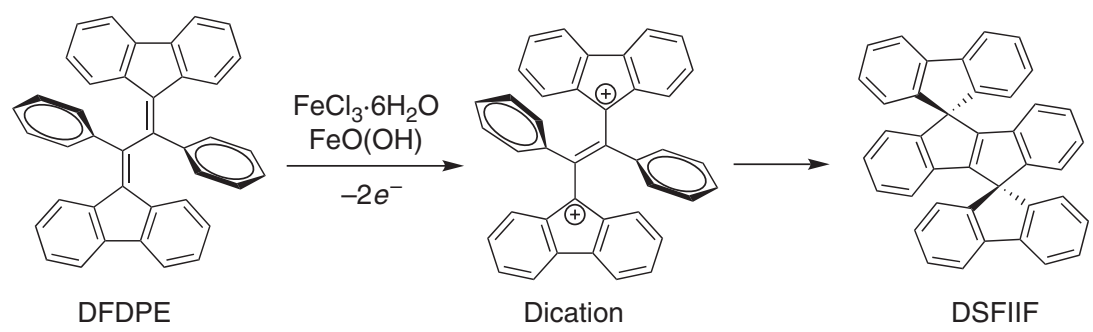

b Oxidative spirocyclization/1,2-aryl migration for $\pi$-extended PAHs: this study

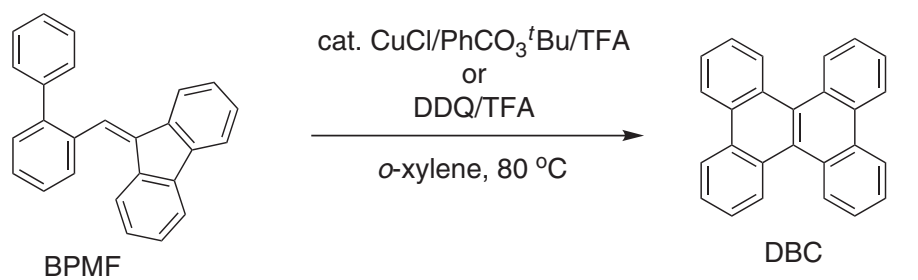

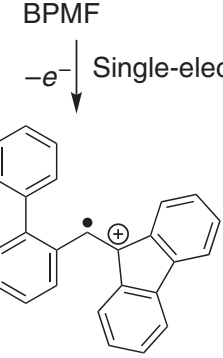

Radical cation $\begin{aligned} & \text { Single-electron oxidation } \\ & \text { and 1,2-aryl migration }\end{aligned} \uparrow-e^{-},-\mathrm{H}^{+}$

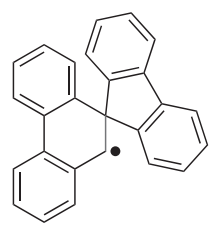

Spirocyclic radical

Figure 1 | Single-electron oxidation of alkenes for synthesis of $\pi$-conjugated polycyclic hydrocarbons. (a) Our previous method for synthesis of dispirofluorene-indenoindenefluorene (DSFIIF) via $\mathrm{FeCl}_{3}$-promoted oxidative spirocyclization of 1,2-di(9H-fluoren-9-ylidene)-1,2-diphenylethane (DFDPE). (b) This study for the single-electron oxidation induced spirocyclization and 1,2-aryl migration tandem synthesis of PAHs. 


\section{Results}

Investigation of single-electron oxidation conditions. Based on our previous oxidative spirocyclization ${ }^{18}$, we firstly examined the weak acidic oxidant $\mathrm{FeCl}_{3}$ using the readily available substrate 1a (Table 1, see also Supplementary Methods). Unfortunately, the use of $\mathrm{FeCl}_{3} / \mathrm{FeO}(\mathrm{OH})$ neutral systems resulted in no reaction, while the acidic $\mathrm{FeCl}_{3}$ in $o$-xylene at $80^{\circ} \mathrm{C}$ only produced the spirocyclic product 3a (vide infra, Fig. 6) in $88 \%$ yield without formation of the desired product 2a. After investigation of various copper catalysts $(20 \mathrm{~mol} \%)$ combined with molecular oxygen ( $1 \mathrm{~atm}$ ) in the presence of trifluoroacetic acid (TFA; 5 equiv), we were pleased to find that the desired tandem reaction did proceed with $\mathrm{CuCl}$ catalyst/ $\mathrm{O}_{2}$ systems, affording the corresponding product $\mathbf{2 a}$ in $39 \%$ yield (Table 1 , entry 1 ). The use of other oxidants such as tert-butyl hydroperoxide (TBHP) and di-tertbutyl peroxide (DTBP) in place of $\mathrm{O}_{2}$ have no beneficial effect in achieving a high yield of $\mathbf{2 a}$ (entries 2 and 3). To our delight, the yield of 2a was improved significantly when $\mathrm{PhI}(\mathrm{OAc})_{2}$ and $\mathrm{PhCO}_{3}{ }^{t} \mathrm{Bu}$ were used as oxidants in conjunction with the $\mathrm{CuCl}$ catalyst (entries 4 and 5); particularly, the latter oxidant produced 2a in nearly quantitative yield. The combination of a $\mathrm{Cu}(\mathrm{I})$ salt with $\mathrm{PhCO}_{3}{ }^{t} \mathrm{Bu}$ was reported to enable the formation of a $\mathrm{PhCO}_{2} \mathrm{Cu}$ (II) salt along with a ${ }^{t} \mathrm{BuO}$ radical species in situ to generate a allylic radical ${ }^{29}$, thus suggesting the involvement of a radical mechanism in the present tandem reaction. The use of $\mathrm{PhCO}_{3}{ }^{t} \mathrm{Bu}$, DTBP and $\mathrm{PhI}(\mathrm{OAc})_{2}$ as oxidants in the absence of the copper catalyst led to poor yields of $2 \mathrm{a}$ (entries 6-8), indicating the important role of the copper catalyst in the $\mathrm{Cu}(\mathrm{I})$ /oxidant systems. Further screening of other oxidants in the absence of the copper catalyst revealed that 2,3-dichloro-5,6dicyanobenzoquinone (DDQ) and $o$-chloranil were also effective in achieving high yields of $\mathbf{2 a}$ (entries 9 and 10). It was noted that the use of TFA as an additive was necessary for rendering this transformation; the strong acid such as trifluoromethanesulfonic acid ( $\mathrm{TfOH}$ ) gave the spirocycle $\mathbf{3 a}$ in $95 \%$ yield, while the weak acid such as acetic acid resulted in no reaction. It has been demonstrated that the DDQ/strong acid system readily undergoes a single-electron oxidation of various electron donors with high oxidation potentials to afford the corresponding radical cation species $^{23,30-32}$, implying the present transformation involves the radical cation formation process.

Synthesis of various PAHs with versatile functional groups. With the optimized conditions obtained from entries 5 and 9 in Table 1 as conditions A and B, the electronic effect of substituents on the fluorene and biphenyl moieties in the starting BPMFs was investigated to understand the influence on the construction of the DBC scaffold (Fig. 2). The reaction of $\mathbf{1 b}$ with two electronrich $t$-butyl substituents on the fluorene moiety under condition A afforded a higher yield of the corresponding DBC $\mathbf{2 b}$ than that under condition B. Likewise, the condition A showed higher activity than the condition $B$ for the reactions of $\mathbf{1 c}$ and $1 \mathbf{d}$ with two electron-poor substituents such as $\mathrm{Br}$ and $\mathrm{I}$ as $\mathrm{R}^{1}$. The electron-rich substrate $\mathbf{1 b}$ showed much higher reactivity as compared to the electron-poor substrates 1c and 1d under both conditions A and B. Similar electronic effects were also observed from the substrates with substituents on the biphenyl moiety. For example, the reactions of $\mathbf{1 e}$ and $\mathbf{1 f}$ with two electron-rich substituents such as $\mathrm{Me}$ and $\mathrm{MeO}$ as $\mathrm{R}^{2}$ produced the corresponding DBCs $2 \mathrm{e}$ and $\mathbf{2 f}$ in high yields under both conditions $\mathrm{A}$ and $\mathrm{B}$, while the reactions of $\mathbf{1 g}$ and $\mathbf{1 h}$ having two electron-withdrawing substituents such as $\mathrm{F}$ and $\mathrm{Cl}$ as $\mathrm{R}^{2}$ afforded the corresponding products $\mathbf{2 g}$ and $\mathbf{2 h}$ in lower yields with longer reaction times. The BPMF $\mathbf{1 i}$ and its perdeuterated analogue $\mathbf{1 i}-\boldsymbol{d}_{\mathbf{5}}$ bearing electron-donating $t$-butyl and methoxy groups at fluorene and biphenyl moieties showed a high reactivity, which underwent the tandem annulation at $40^{\circ} \mathrm{C}$ under both conditions $\mathrm{A}$ and $\mathrm{B}$ to afford the corresponding DBC derivatives $2 \mathbf{i}$ and $\mathbf{2} \mathbf{i}-\boldsymbol{d}_{\mathbf{4}}$ in good yields and no $\mathrm{D}-\mathrm{H}$ exchanged products were observed for the reaction of $1 \mathbf{i}-\boldsymbol{d}_{5}$. In the reactions of the benzothiophene-substituted substrate $\mathbf{1 j}$, the DDQ-mediated condition B showed higher activity than the $\mathrm{Cu}$-catalysed condition $\mathrm{A}$, giving the corresponding $\mathrm{DBC}$ derivative $\mathbf{2} \mathbf{j}$ in moderate yields. Interestingly, the tandem reaction of $\mathbf{1} \mathbf{k}$ composed of binaphthyl instead of biphenyl also proceeded efficiently, giving rise to the helicene product $2 \mathbf{k}$ in high yields ${ }^{33}$.

The growing interests in the synthesis and potential application of extended PAHs as graphene molecules in optoelectronics led

Table 1 | Optimization of oxidation conditions.

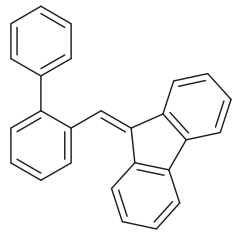

1a

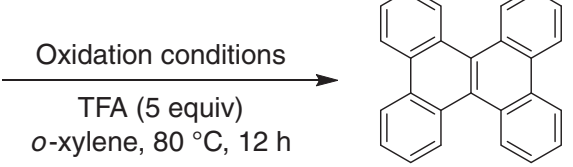

2a

\begin{tabular}{|c|c|c|c|}
\hline Entry & Cu catalyst & Oxidant & Yield of $2 a(\%)^{\star}$ \\
\hline 1 & $\mathrm{CuCl}$ & $\mathrm{O}_{2}(1 \mathrm{~atm})$ & 39 \\
\hline 2 & $\mathrm{CuCl}$ & TBHP & 7 \\
\hline 3 & $\mathrm{CuCl}$ & DTBP & 16 \\
\hline $5^{\dagger}$ & $\mathrm{CuCl}$ & $\mathrm{PhCO}_{3}{ }^{t} \mathrm{Bu}$ & $100(94)$ \\
\hline 6 & - & $\mathrm{PhCO}_{3}{ }^{t} \mathrm{Bu}$ & 4 \\
\hline 7 & - & DTBP & 2 \\
\hline 10 & - & o-chloranil & 85 \\
\hline
\end{tabular}



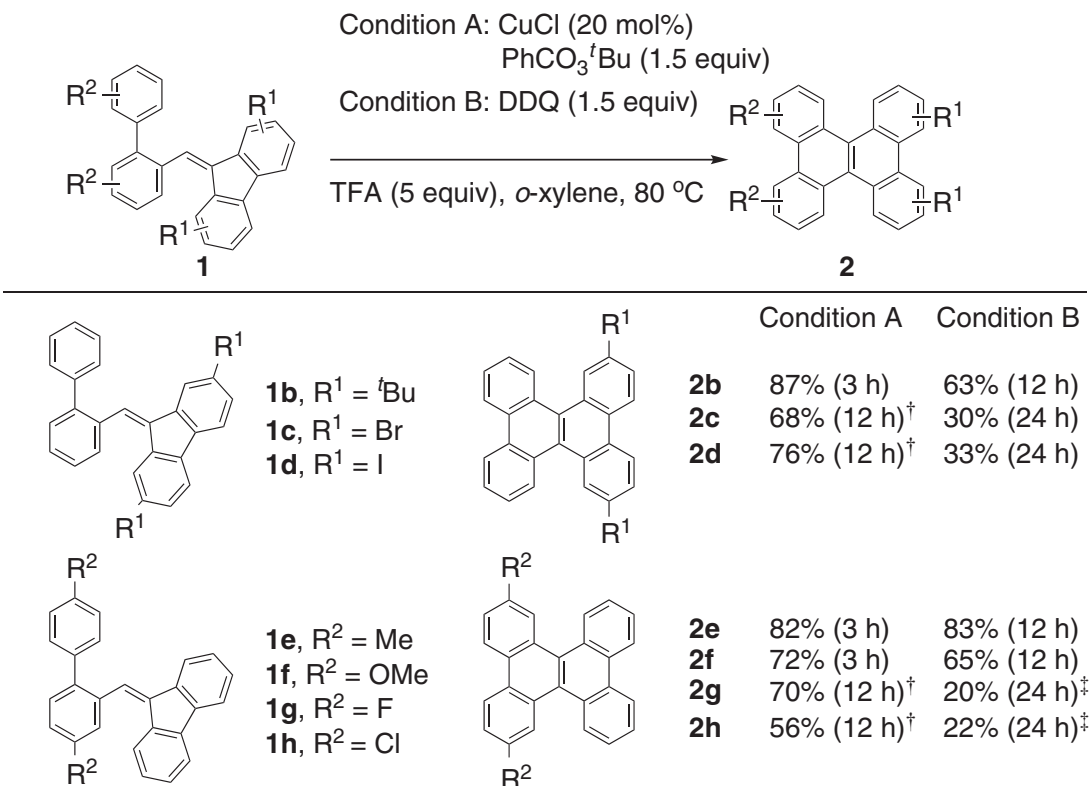

1e, $\mathrm{R}^{2}=\mathrm{Me}$

1f, $R^{2}=O M e$

$1 \mathrm{~g}, R^{2}=F$

$1 \mathrm{~h}, \mathrm{R}^{2}=\mathrm{Cl}$<smiles>[R]c1ccc2c3ccccc3c3c4ccccc4c4ccccc4c3cc1-2</smiles>

$\begin{array}{lll}\mathbf{2 e} & 82 \%(3 \mathrm{~h}) & 83 \%(12 \mathrm{~h}) \\ \mathbf{2 f} & 72 \%(3 \mathrm{~h}) & 65 \%(12 \mathrm{~h}) \\ \mathbf{2 g} & 70 \%(12 \mathrm{~h})^{\dagger} & 20 \%(24 \mathrm{~h})^{\dagger} \\ \mathbf{2 h} & 56 \%(12 \mathrm{~h})^{\dagger} & 22 \%(24 \mathrm{~h})^{\dagger}\end{array}$<smiles>COc1ccc(-c2ccccc2)c(/C=C2/c3cc(C)ccc3-c3ccc(C(C)(C)C)cc32)c1</smiles>

$1 \mathbf{i}$<smiles>COc1ccc2c3ccccc3c3c4cc(Br)ccc4c(C(C)(C)C)cc3c2c1</smiles>

2i $\quad 70 \%(3 h)^{\perp} \quad 64 \%(3 h)^{\perp}$

${ }^{t} \mathrm{Bu}$<smiles></smiles><smiles></smiles>

2i- $\boldsymbol{d}_{\mathbf{4}} \quad 60 \%(3 \mathrm{~h})^{\perp} \quad 72 \%(3 \mathrm{~h})^{\perp}$

$1 \mathrm{i}-d_{5}$<smiles></smiles>

$1 \mathrm{j}$<smiles></smiles>

2j

$23 \%(12 \mathrm{~h})$

$55 \%(12 h)$
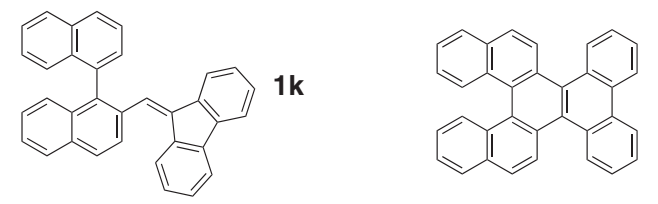

2k $86 \%(3 \mathrm{~h})$

$93 \%(12 h)$

Figure 2 | Substrate scope of oxidative aromatization. The isolated yields are shown. ${ }^{\dagger} \mathrm{CuCl}(40 \mathrm{~mol} \%), \mathrm{PhCO}_{3}{ }^{t} \mathrm{Bu}(3$ equiv) and TFA (10 equiv) were used. ${ }^{\ddagger}$ DDQ ( 3 equiv) and TFA (10 equiv) were used. ${ }^{\perp}$ The reaction temperature is $40^{\circ} \mathrm{C}$.

us to examine the construction of highly extended PAHs using the present tandem reaction ${ }^{1-4}$. In contrast to the activity for the synthesis of the DBC scaffold, the CuCl-catalysed condition A was less active than the DDQ-mediated condition $\mathrm{B}$ for the construction of the following extended PAHs. Under condition A, the double annulation reaction of $\mathbf{1 l}$ containing two biphenylcentered methylenefluorene moieties produced the corresponding hexabenzo[a,c,fg,j,l,op]tetracene $\mathbf{2 l}$ in a low yield of $10 \%$ (Fig. 3a). It was noted that the monoannulated product $2 \mathbf{2 l}^{\prime}$ was dominantly formed in $60 \%$ yield (see Supplementary Information for the structure of $2 \mathbf{I}^{\prime}$ ). To our delight, the yield of $2 \mathbf{l}$ increased to $55 \%$ under the DDQ-mediated condition B with the formation of $2 \mathbf{l}^{\prime}$ in $16 \%$ yield. The structure of $\mathbf{2 l}$ was recently reported to possess an interesting helically twisted conformation ${ }^{14}$. We also examined the double annulation of the p-terphenyl-centered methylenefluorene substrates $\mathbf{1 m}$ and $\mathbf{1 n}$ (Fig. 3b). The reaction of $\mathbf{1 m}$ under condition $\mathrm{B}$ proceeded well to afford the corresponding tetrabenzo $[a, c, f, m]$ phenanthro $[9,10-k]$ tetraphene $2 \mathrm{~m}$ (ref. 34 ) in $88 \%$ yield, while only a $20 \%$ yield of $\mathbf{2 m}$ was obtained under condition $\mathrm{A}$. The combination of the $\mathrm{CuCl}$ catalyst with DDQ (condition C) further increased the yield of $2 \mathbf{m}$ to $95 \%$. Although the condition B was not sufficiently effective for the double annulation of the $t$-butyl-substituted substrate $\mathbf{1 n}$, fortunately, the condition $\mathrm{C}$ provided the corresponding product $\mathbf{2 n}$ (ref. 13) in a high yield of $86 \%$. The present method was also successfully applied to the synthesis of several novel $\pi$-extended PAHs. When the $m$-terphenyl-centered methylenefluorene 10 was subjected to both conditions A and B, 
a<smiles>C(=C1c2ccccc2-c2ccccc21)c1ccccc1-c1ccccc1C=C1c2ccccc2-c2ccccc21</smiles>

11

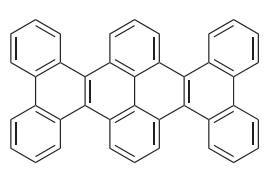

2) $10 \%(\mathrm{~A})$ $55 \%(B)$

b<smiles></smiles>

Condition $\mathrm{A}: \mathrm{CuCl}(40 \mathrm{~mol} \%)$ $\mathrm{PhCO}_{3}{ }^{t} \mathrm{Bu}$ (3 equiv)

Condition B: DDQ (3 equiv) Condition C: $\mathrm{CuCl}(40 \mathrm{~mol} \%)$ DDQ (3 equiv)

TFA (10 equiv) o-xylene, $80^{\circ} \mathrm{C}, 48 \mathrm{~h}$

$$
1 \mathrm{~m}, \mathrm{R}=\mathrm{H}
$$

1n, $R={ }^{t} \mathrm{Bu}$

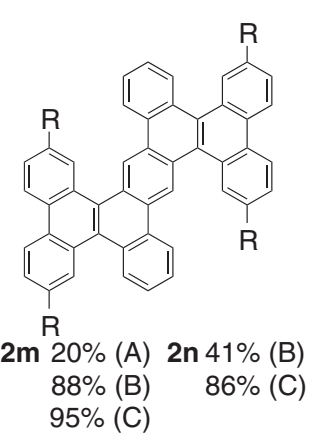

C<smiles>C(=C1c2ccccc2-c2ccccc21)c1cc(C=C2c3ccccc3-c3ccccc32)c(-c2ccccc2)cc1-c1ccccc1</smiles>

10
Condition A: $\mathrm{CuCl}$ (40 mol\%) $\mathrm{PhCO}_{3}{ }^{t} \mathrm{Bu}$ (3 equiv) Condition B: DDQ (3 equiv)

TFA (10 equiv) o-xylene, $80^{\circ} \mathrm{C}, 48 \mathrm{~h}$

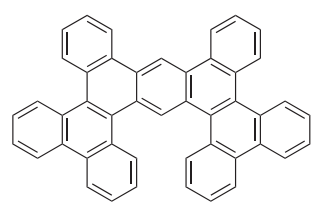

$2032 \%$ (A) $\frac{\text { Condition B: DDQ (3 equiv) }}{\mathrm{TFA}(10 \text { equiv) }} \begin{gathered}\text { o-xylene, } 80^{\circ} \mathrm{C}, 48 \mathrm{~h} \\ { }_{\mathrm{B}}^{\mathrm{Bu}} \mathrm{Bu}\end{gathered}$

$1 \mathrm{p}$

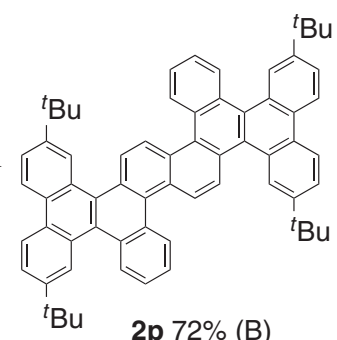

2 p $72 \%(B)$

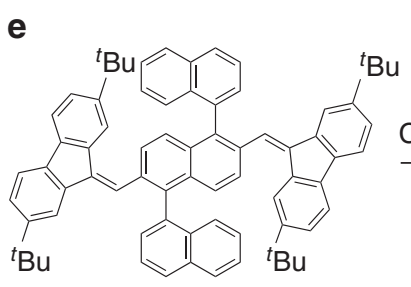

$1 q$
Condition B: DDQ (3 equiv)

TFA (10 equiv) o-xylene, $80^{\circ} \mathrm{C}, 24 \mathrm{~h}$

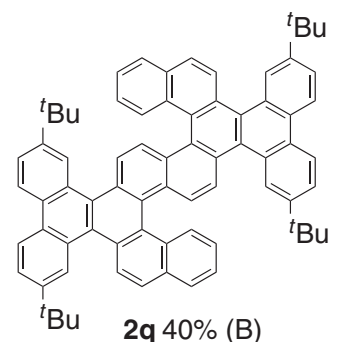

Figure 3 | Synthesis of extended PAHs. Double annulations of (a) biphenyl-centered bis-methylenefluorenes, (b) p-terphenyl-centered bis-methylenefluorenes, (c) $m$-terphenyl-centered bis-methylenefluorenes, (d) 1,5-diphenylnaphthalene-centered bis-methylenefluorenes and (e) $1,1^{\prime}: 5^{\prime}, 1^{\prime \prime}$-ternaphthalene-centered bis-methylenefluorenes.

the corresponding new PAH of tetrabenzo $[a, c, f, k]$ phenanthro $[9,10-m]$ tetraphene 20 was obtained in $32 \%$ and $86 \%$, respectively (Fig. 3c). Moreover, the 1,5-diphenylnaphthalene-centered methylenefluorene $\mathbf{1 p}$ also underwent the double tandem annulation efficiently under condition $\mathrm{B}$ to afford the novel $\pi$-extended PAH $\mathbf{2 p}$ in $72 \%$ yield, while the condition A resulted in decomposition of 1p (Fig. 3d). Remarkably, a novel $\pi$-extended $S$-type helicene product $\mathbf{2 q}$ could be constructed in $40 \%$ yield upon the double annulation of the $1,1^{\prime}: 5^{\prime}, 1^{\prime \prime}$-ternaphthalene-centered methylenefluorene $\mathbf{1 q}$ under condition B (Fig. 3e). The different activity of conditions A to C awaits further clarification with respect to the yield and reactivity, but we assumed that the electron distribution of benzene components in various substrates should highly affect the single-electron oxidation of the alkene moiety.

We also examined the triaryl-substituted ethene $1 \mathbf{r}$ bearing a diphenylmethylene unit instead of the fluorene moiety (Fig. 4). As expected, the reaction of $\mathbf{1 r}$ underwent the present tandem 
reaction efficiently, affording the corresponding 9,10-diphenylphenanthrene $\mathbf{2 r}$ in high yields under both conditions A and B. Other biphenyl-substituted ethenes replacing the 2,2-diphenyl unit in $1 \mathbf{r}$ with different substituents, such as $\mathrm{Ph}$ and $\mathrm{Me}, \mathrm{Ph}$ and $\mathrm{H}$, dimethyl and two hydrogens were examined to be totally inactive, demonstrating the importance of triaryl groups for the implementation of the present tandem transformation. The aryl groups are thought to be crucial for the radical cation stabilization and 1,2-aryl migration tandem process as shown in Fig. 7.

Optical and electrochemical properties of $2 \mathbf{k}-\mathbf{q}$. The ultravioletvisible absorption of extended PAHs of $\mathbf{2 p}(426 \mathrm{~nm})$ and $\mathbf{2 q}$ $(432 \mathrm{~nm})$ in diluted chloroform solution show red-shifted onsets compared to that of $\mathbf{2 k - o}$ due to their large $\pi$-extension lengths (Table 2 and Fig. 5). The fluorescence spectra of the extended PAHs have emission maxima at the region of $436-475 \mathrm{~nm}$ and exhibit relatively large Stock shifts in the range of $17-65 \mathrm{~nm}$, implying their weak structural rigidity. Interestingly, the $S$-type helicene $\mathbf{2 q}$ exhibits a much smaller Stock shift

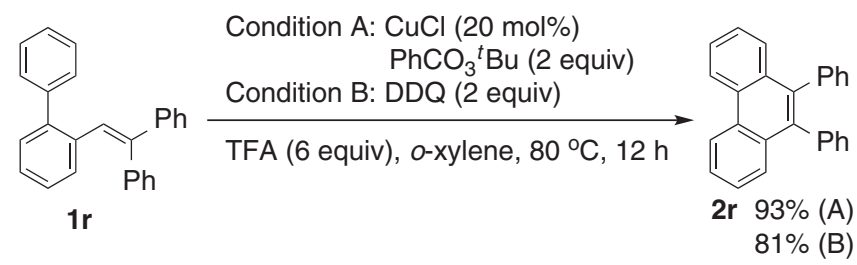

Figure 4 | Construction of phenanthrene motif. The reaction with nonfluorenyl substrate $\mathbf{1 r}$ is able to produce the corresponding 9,10diphenylphenanthrene $\mathbf{2} \mathbf{r}$ under the standard conditions. of $17 \mathrm{~nm}$ compared to the simple helicene $2 \mathbf{k}(65 \mathrm{~nm})$, indicating the higher structural rigidity of the former. The compounds $\mathbf{2 l}$, $\mathbf{2 m}$ and $\mathbf{2 p}$ in diluted chloroform have moderate fluorescence quantum yields of $0.27,0.36$ and 0.31 , respectively, which are higher than the compound $20(0.19)$. It was found that both helicene compounds $\mathbf{2 k}(0.06)$ and $\mathbf{2 q}(0.14)$ showed relatively low emission properties. The highest occupied molecular orbital (HOMO) energy level calculated from the oxidation potential by cyclic voltammetry (Supplementary Fig. 2) shows that the helicene $2 \mathbf{k}$ has the lowest HOMO of $-5.65 \mathrm{eV}$ and 20 has the highest $\mathrm{HOMO}$ of $-5.25 \mathrm{eV}$ compared to that of other four PAHs $(-5.42$ to $-5.50 \mathrm{eV})$. The lowest unoccupied molecular orbital (LUMO) energy level estimated from the HOMO and the optical energy gap shows that $\mathbf{2 k}, \mathbf{2 m}, \mathbf{2} \mathbf{p}$ and $\mathbf{2 q}$ have lower LUMOs in the range of -2.51 to $-2.63 \mathrm{eV}$ compared to the PAHs $21(-2.37 \mathrm{eV})$ and $20(-2.18 \mathrm{eV})$. The large extended PAHs $\mathbf{2 p}$ and $\mathbf{2 q}$ show smaller HOMO-LUMO gaps than that of other PAHs, which is attributed to the decreased LUMO orbitals more than their HOMO orbitals.

\section{Discussion}

To further understand the reaction pathways, the spirocyclic compound 3a was used as a starting substrate under both conditions A and B (Fig. 6), which was prepared as a byproduct during the optimization of reaction conditions. Although the yields of the desired product $\mathbf{2 a}$ were relatively low, the oxidation reactions did proceed under the standard conditions, suggesting the formation of spirocyclic radical $\mathbf{B}$ and cation $\mathbf{C}$ intermediates (Fig. 7) through the sequential single-electron oxidation of $\mathbf{3 a}$. The formation of the cation species $\mathbf{C}$ may give rise to subsequent 1,2-aryl shift to produce the final product $2 \mathbf{a}$. It should be mentioned that, however, the present tandem reaction of $1 \mathbf{a}$ to $\mathbf{2 a}$

Table 2 | Optical and electrochemical properties of $2 k-q$.

\begin{tabular}{|c|c|c|c|c|c|c|}
\hline Compound & $\lambda_{\text {onset }}(\mathrm{nm})^{\star}$ & $\lambda_{\mathrm{em}}^{\max }\left(\lambda_{\mathrm{exc}}\right)(\mathrm{nm})^{\star}$ & $\Phi_{\mathbf{f}}^{\dagger}$ & $\Delta E^{\text {opt }}(\mathrm{eV})^{\ddagger}$ & HOMO (eV) ${ }^{\S}$ & LUMO (eV)|| \\
\hline $2 k$ & 405 & $443,456(320)$ & 0.06 & 3.06 & -5.65 & -2.59 \\
\hline 21 & 406 & $437(320)$ & 0.27 & 3.05 & -5.42 & -2.37 \\
\hline $2 m$ & 418 & $436,450(340)$ & 0.36 & 2.97 & -5.48 & -2.51 \\
\hline 20 & 404 & $442,462(300)$ & 0.19 & 3.07 & -5.25 & -2.18 \\
\hline $2 p$ & 426 & $444,462(300)$ & 0.31 & 2.91 & -5.47 & -2.56 \\
\hline $2 q$ & 432 & $458,475(300)$ & 0.14 & 2.87 & -5.50 & -2.63 \\
\hline
\end{tabular}

*Ultraviolet-visible absorption fluorescence spectra were measured in chloroform.

†Absolute fluorescence quantum yield $\left(\Phi_{\mathrm{f}}\right)$ was measured by a photon-counting method using an integration sphere.

tOptical energy gap $\left(\Delta E^{\text {opt }}\right.$ ) was estimated from the contact between the ultraviolet visible absorption and the fluorescence spectra according to the equation, $\Delta E^{\text {opt }}$ ( $\mathrm{eV}$ ) $=1,240 / \lambda_{\text {onse }}$ $\$ \mathrm{HOMO}$ was calculated from the oxidation potential.

IILUMO was calculated from the HOMO energy and the optical energy gap.
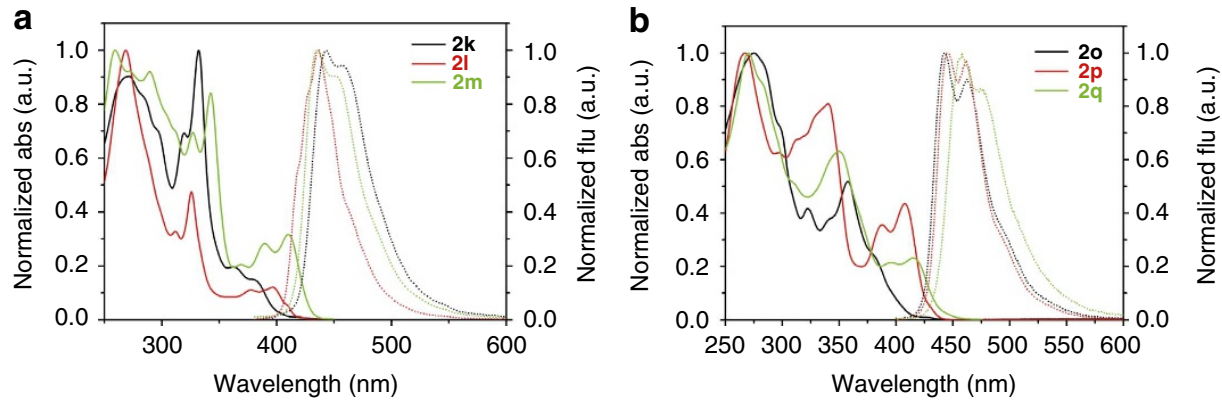

Figure 5 | Ultraviolet-visible absorption and fluorescence spectra of extended PAHs. The ultraviolet-visible absorption (solid line) and fluorescence spectra (dash line) of $\mathbf{2} \mathbf{k}-\mathbf{m}$ (a), and $\mathbf{2 0 - \mathbf { q }}(\mathbf{b})$ in diluted chloroform. The ultraviolet-visible absorption red-shifted as expending their $\pi$-conjugation lengths. The extended PAHs possess relatively large Stock shifts, indicating their weak structural rigidity. 
may not involve the formation of $\mathbf{3} \mathbf{a}$ by the $\mathrm{H}$ atom abstraction. In addition, an intermolecular competing reactions between the protonated substrate $\mathbf{1 i}$ and the perdeuterated substrate $\mathbf{1 i}-\boldsymbol{d}_{\mathbf{5}}$ were studied in the same reaction vessel to understand the kinetic isotope effects (KIEs; Supplementary Fig. 3). When a 1:1 mixture of $1 \mathbf{i}$ and $1 \mathbf{i}-d_{5}$ was heated at $40^{\circ} \mathrm{C}$ for $1 \mathrm{~h}$ under conditions $\mathrm{A}$ and $\mathrm{B}$, respectively, the corresponding products $2 \mathbf{i}$ and $2 \mathbf{i}-\boldsymbol{d}_{\mathbf{4}}$ were obtained with similar KIE values of 1.21 and 1.20. The small isotope effect suggests that the present reaction involves a rapid aromatic deprotonation process and in other words, the $\mathrm{C}-\mathrm{C}$ bond formation or cleavage steps can be presumed to be the rate-determining.

The proposed reaction mechanism is outlined in Figure 7 in terms of the experimental information, such as the indispensable role of single-electron oxidants, electronic effect of substrates, control reaction with the spirocyclic substrate and KIE values. Initially, a single-electron oxidation takes place at the more electron-rich alkene moiety of $\mathbf{1 a}$ by the $\mathrm{CuCl} / \mathrm{PhCO}_{3}{ }_{3} \mathrm{Bu}$ or DDQ oxidation system to form a radical cation species A (refs 9,35). Subsequently, the spirocyclization proceeds through the intramolecular Friedel-Craft reaction to afford a spirocyclic radical species $\mathbf{B}$, which may undergo a second single-electron oxidation by the excess oxidants to form a spirocyclic cation $\mathbf{C}$.

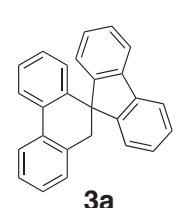

$3 a$
Condition A: $\mathrm{CuCl}(20 \mathrm{~mol} \%)$

$\mathrm{PhCO}_{3}{ }^{t} \mathrm{Bu}$ (1.5 equiv) Condition B: DDQ (1.5 equiv)

TFA (5 equiv), o-xylene, $80^{\circ} \mathrm{C}, 12 \mathrm{~h}$

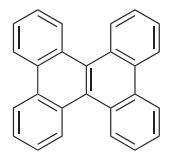

2a $9 \%(3 a, 80 \% ; A)$ $58 \%(3 a, 42 \% ; B)$
Figure 6 | Reactions using the spirocyclic substrate 3a for the formation of $\mathbf{2 a}$. Both single-electron oxidation conditions $A$ and $B$ afforded the corresponding product $\mathbf{2} \mathbf{a}$, indicating the involvement of spirocyclic radical species $\mathbf{B}$ and $\mathbf{C}$ for subsequent 1,2-aryl migration.
Next, the direct 1,2-aryl migration ${ }^{36-38}$ of the cation $\mathbf{C}$ or more likely through an arenium cation intermediate $\mathbf{D}$ affords the cation $\mathbf{E}$, which undergoes the rapid deprotonation to give the stable aromatic product $\mathbf{2 a}$.

In summary, we have disclosed a novel and efficient tandem synthetic method for the construction of various extended PAHs by the single-electron oxidation of various (o-biphenylyl)methylene-substituted fluorenes. The selective single-electron oxidation of the alkene moiety by the $\mathrm{Cu}$ catalyst/ $\mathrm{PhCO}_{3}{ }^{t} \mathrm{Bu}$ or DDQ oxidation system in the presence of TFA enabled the subsequent spirocyclization and 1,2-aryl migration tandem process to take place. Following this method, various known and new extended PAHs including the functionalized DBCs, benzo[f]naphtho[1,2-s]picene, hexabenzo[ $[a, c, f g, j, l, o p]$ tetracene, tetrabenzo $[a, c, f, m]$ phenanthro $[9,10-k]$ tetraphene, tetrabenzo $[a, c, f, k]$ phenanthro[9,10-m] tetraphene, tetrabenzo $[a, c, f, o]$ phenanthro $[9,10-m]$ picene and $S$-type helicene have been readily synthesized. Further extension of the present tandem synthetic strategy to a new class of $\pi$-extended polycycles with diverse ring systems is in progress.

\section{Methods}

Materials. For NMR spectra of compounds in this manuscript, see Supplementary Figs 4-52. For the calculated electron distribution of HOMO orbital of 1a, see Supplementary Fig. 1. For the cyclic voltammograms of compounds $2 \mathbf{k}-\mathbf{m}$ and 2o-q, see supplementary Fig. 2. For the KIE experiments, see Supplementary Fig. 3. For the general information, experimental procedures and analytic data of compounds synthesized, see Supplementary Methods.

General procedure for synthesis of $\mathbf{2 a}$. To a $o$-xylene $(1.2 \mathrm{ml})$ solution of $\mathrm{CuCl}$ ( $4 \mathrm{mg}, 20 \mathrm{~mol} \%)$ and $\mathrm{PhCO}_{3}{ }^{t} \mathrm{Bu}(58.3 \mathrm{mg}, 0.3 \mathrm{mmol}$ ) (condition A) or DDQ (68.1 mg, $0.3 \mathrm{mmol}$, condition B) were added TFA (114 mg, $1 \mathrm{mmol})$ and BPMF (1a) $(66 \mathrm{mg}, 0.2 \mathrm{mmol})$ at room temperature. The mixture was heated at $80^{\circ} \mathrm{C}$ for $1.5 \mathrm{~h}$ (condition A) or $12 \mathrm{~h}$ (condition B). After cooling to room temperature, the reaction mixture was monitored by TLC and GC-MS. The reaction mixture was washed with water and extracted with $\mathrm{CH}_{2} \mathrm{Cl}_{2}$ for 2 times. After concentration of the $\mathrm{CH}_{2} \mathrm{Cl}_{2}$ solution, the resulting residue was purified by flash silica gel chromatography using a mixture of $\mathrm{CH}_{2} \mathrm{Cl}_{2}$ /hexane as eluent to give the corresponding product $2 \mathrm{a}$ in $94 \%$ yield $(61.8 \mathrm{mg}$, condition $\mathrm{A})$ or in $87 \%$ yield $(57.2 \mathrm{mg}$, condition B) as a colourless solid.

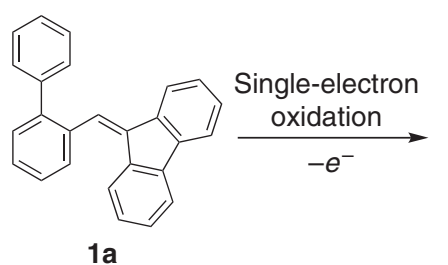

1 a<smiles>c1ccc2c(c1)c1ccccc1c1c3ccccc3c3ccccc3c21</smiles>

$2 a$

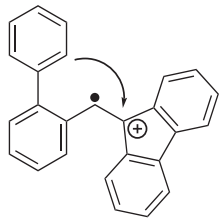

Radical cation A

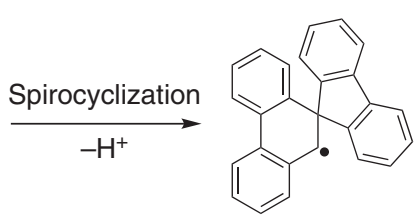

Radical B
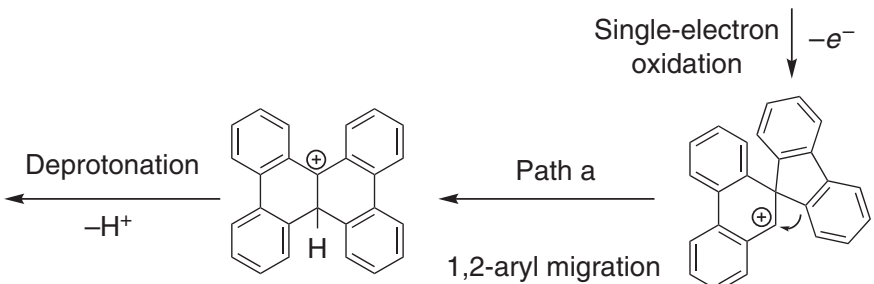

Cation E

Cation $\mathbf{C}$

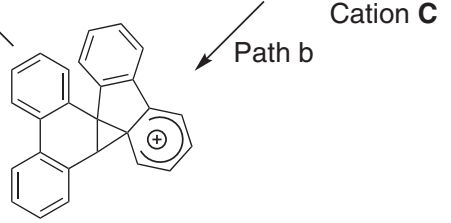

Arenium cation D

Figure 7 | Proposed tandem reaction mechanism. Initially, the reaction takes place via a single-electron oxidation of the relatively electron-rich alkene moiety of 1a, followed by the intramolecular Friedel-Crafts reaction to form a spirocyclic radical species $\mathbf{B}$, which is further oxidized to give a spirocyclic cation $\mathbf{C}$. The cation $\mathbf{C}$ gives rise to the 1,2-aryl migration followed by aromatization to afford the desired dibenzochrysene $\mathbf{2 a}$. 
Data availability. The authors declare that the data supporting the findings of this study are available within the paper and its Supplementary Information files, and also are available from the corresponding author upon reasonable request.

\section{References}

1. Anthony, J. E. Functionalized acenes and heteroacenes for organic electronics. Chem. Rev. 106, 5028-5048 (2006).

2. Pascal, R. A. Jr. Twisted acenes. Chem. Rev. 106, 4809-4819 (2006).

3. Anthony, J. E. The larger acenes: versatile organic semiconductors. Angew. Chem. Int. Ed. 47, 452-483 (2008).

4. Ye, Q. \& Chi, C. Recent highlights and perspectives on acene based molecules and materials. Chem. Mater. 26, 4046-4056 (2014).

5. Wu, J., Pisula, W. \& Müllen, K. Graphenes as potential material for electronics. Chem. Rev. 107, 718-747 (2007).

6. Chen, L., Hernandez, Y., Feng, X. \& Müllen, K. From nanographene and graphene nanoribbons to graphene sheets: chemical synthesis. Angew. Chem. Int. Ed. 51, 7640-7654 (2012).

7. Narita, A., Feng, X. \& Müllen, K. Bottom-up synthesis of chemically precise graphene nanoribbons. Chem. Rec. 15, 295-309 (2015).

8. Narita, A., Wang, X.-Y., Feng, X. \& Müllen, K. New advances in nanographene chemistry. Chem. Soc. Rev. 44, 6616-6643 (2015).

9. Grzybowski, M., Skonieczny, K., Butenschen, H. \& Gryko, D. T. Comparison of oxidative aromatic coupling and the Scholl reaction. Angew. Chem. Int. Ed. 52, 9900-9930 (2013).

10. Tanaka, K. (ed.) Transition-Metal-Mediated Aromatic Ring Construction (Wiley, 2013).

11. Jin, T., Zhao, J., Asao, N. \& Yamamoto, Y. Metal-catalysed annulation reactions for $\pi$-conjugated polycycles. Chem.-Eur. J. 20, 3554-3576 (2014).

12. Segawa, Y., Maekawa, T. \& Itami, K. Synthesis of extended $\pi$-systems through C-H activation. Angew. Chem. Int. Ed. 54, 66-81 (2015).

13. Ozaki, K., Kawasumi, K., Shibata, M., Ito, H. \& Itami, K. One-shot K-regionselective annulative $\pi$-extension for nanographene synthesis and functionalization. Nat. Commun. 6, 6251 (2015).

14. Yano, Y., Ito, H., Segawa, Y. \& Itami, K. Helically twisted tetracene: synthesis, crystal structure, and photophysical properties of hexabenzo[ $[a, c, f g, j, l, o p]$ tetracene. Synlett 27, 2081-2084 (2016).

15. Mochida, K., Kawasumi, K., Segawa, Y. \& Itami, K. Direct arylation of polycyclic aromatic hydrocarbons through palladium catalysis. J. Am. Chem. Soc. 133, 10716-10719 (2011).

16. Herwig, P., Kayser, C. W., Müllen, K. \& Spiess, H. W. Columnar mesophases of alkylated hexa-peri-hexabenzocoronenes with remarkably large phase widths. Adv. Mater. 8, 510-513 (1996).

17. Fechtenkötter, A., Saalwächter, K., Harbison, M. A., Müllen, K. \& Spiess, H. W. Highly ordered columnar structures from hexa-peri-hexabenzocoronenessynthesis, X-ray diffraction, and solid-state heteronuclear multiple-quantum NMR investigations. Angew. Chem. Int. Ed. 38, 3039-3042 (1999).

18. Zhao, J. et al. $\mathrm{FeCl}_{3}$-mediated oxidative spirocyclization of difluorenylidene diarylethanes leading to dispiro[fluorene-9, $5^{\prime}$-indeno[2,1- $a$ ] indene- $10^{\prime}, 9^{\prime \prime}$. fluorene]s. Angew. Chem. Int. Ed. 55, 259-263 (2016).

19. Yamaguchi, S. \& Swager, T. M. Oxidative cyclization of bis(biaryl)acetylenes: synthesis and photophysics of dibenzo[g,p]chrysene-based fluorescent polymers. J. Am. Chem. Soc. 123, 12087-12088 (2001).

20. Chaudhuri, R. et al. Functionalized dibenzo[g,p]chrysenes: variable photophysical and electronic properties and liquid-crystal chemistry. Org. Lett. 10, 3053-3056 (2008)

21. Shimizu, M., Nagao, I., Tomioka, Y. \& Hiyama, T. Palladium-catalysed annulation of vic-bis(pinacolatoboryl)alkenes and -phenanthrenes with 2,2'dibromobiaryls: facile synthesis of functionalized phenanthrenes and dibenzo[g,p]chrysenes. Angew. Chem. Int. Ed. 47, 8096-8099 (2008).

22. Navale, T. S., Zhai, L., Lindeman, S. V. \& Rathore, R. Octamethoxydibenzochrysene: isolation and X-ray crystallographic characterization of a twisted polyaromatic cation radical. Chem. Commun. doi:10.1039/B903133B (2009).

23. Zhai, L., Shukla, R. \& Rathore, R. Oxidative C - C bond formation (Scholl reaction) with DDQ as an efficient and easily recyclable oxidant. Org. Lett. 11, 3474-3477 (2009).

24. Tsuji, H., Ueda, Y., Ilies, L. \& Nakamura, E. Synthesis of tetrasubstituted alkenes by stereo- and regioselective stannyllithiation of diarylacetylenes. J. Am. Chem. Soc. 132, 11854-11855 (2010).

25. Navale, T. S., Thakur, K. \& Rathore, R. Sequential oxidative transformation of tetraarylethylenes to 9,10-diarylphenanthrenes and dibenzo $[g, p]$ chrysenes using DDQ as an oxidant. Org. Lett. 13, 1634-1637 (2011).

26. Ueda, Y., Tsuji, H., Tanaka, H. \& Nakamura, E. Synthesis, crystal packing, and ambipolar carrier transport property of twisted dibenzo[g,p]chrysenes. Chem. Asian J. 9, 1623-1628 (2014).
27. Suzuki, N., Fujita, T. \& Ichikawa, J. Method for the synthesis of dibenzo[g,p]chrysenes: domino Friedel - Crafts-type cyclization of difluoroethenes bearing two biaryl groups. Org. Lett. 17, 4984-4987 (2015).

28. Ma, J. et al. Palladium-catalysed annulation of $2,2^{\prime}$-dibromobiphenyls with alkynes: synthesis of functionalized phenanthrenes and dibenzochrysenes. Synlett 26, 1991-1996 (2015).

29. Eames, J. \& Watkinson, M. Catalytic allylic oxidation of alkenes using an asymmetric Kharasch-Sosnovsky reaction. Angew. Chem. Int. Ed. 40, 3567-3571 (2001).

30. Rathore, R. \& Kochi, J. K. Acid catalysis versus electron-transfer catalysis via organic cations or cation-radicals as the reactive intermediate. Are these distinctive mechanisms? Acta Chem. Scand. 52, 114-130 (1998).

31. Rathore, R., Zhu, C.-J., Lindeman, S. V. \& Kochi, J. K. Spontaneous oxidation of organic donors to their cation radicals using Brønsted acids. Identification of the elusive oxidant. J. Chem. Soc. Perkin Trans. 2, 1837-1840 (2000).

32. Zhai, L., Shukla, R., Wadumethrige, S. H. \& Rathore, R. Probing the arenium-ion (protontransfer) versus the cation-radical (electron transfer) mechanism of Scholl reaction using DDQ as oxidant. J. Org. Chem. 75, $4748-4760$ (2010).

33. Kashihara, H., Asada, T. \& Kamikawa, K. Synthesis of a double helicene by a palladium-catalysed cross-coupling reaction: structure and physical properties. Chem.-Eur. J. 21, 6523-6527 (2015).

34. Ma, J., Lin, T., Pan, X. \& Wang, W. Graphene-like molecules based on tetraphenylethene oligomers: synthesis, characterization, and applications. Chem. Mater. 26, 4221-4229 (2014).

35. Suzuki, T., Higuchi, H., Ohkita, M. \& Tsuji, T. Dual-mode electrochromism switched by proton transfer: dynamic redox properties of bis(diarylmethylenium)-type dyes. Chem. Commun. doi:10.1039/B104742F (2001).

36. Harvey, R. G., Abu-Shaqara, E. \& Yang, C. An efficient synthesis of the sterically strained hydrocarbon tetrabenzo[de,hi,mn,qr]naphthacene. J. Org. Chem. 58, 5866 (1993).

37. Skraba-Joiner, S. L., McLaughlin, E. C., Ajaz, A., Thamatam, R. \& Johnson, R. P. Scholl cyclizations of aryl naphthalenes: rearrangement precedes cyclization. J. Org. Chem. 80, 9578-9583 (2015).

38. Liu, J. et al. Unexpected Scholl reaction of 6,7,13,14-tetraarylbenzo[k]tetraphene: selective formation of five-membered rings in polycyclic aromatic hydrocarbons. J. Am. Chem. Soc. 138, 2602-2608 (2016).

\section{Acknowledgements}

This work was supported by JSPS KAKENHI grant number 15KK0180 on Fostering Joint International Research and World Premier International Research Center Initiative (WPI), MEXT, Japan.

\section{Author contributions}

T.J. conceived the methodology and wrote the manuscript with the assistance of other authors. X.Z., Z.X. and W.S. conducted experiments. K.O. performed theoretical calculations. All the authors analysed the data.

\section{Additional information}

Supplementary Information accompanies this paper at http://www.nature.com/ naturecommunication

Competing interests: The authors declare no competing financial interests.

Reprints and permission information is available online at http://npg.nature.com/ reprintsandpermissions/

How to cite this article: Zhang, X. et al. Synthesis of extended polycyclic aromatic hydrocarbons by oxidative tandem spirocyclization and 1,2-aryl migration. Nat. Commun. 8, 15073 doi: 10.1038/ncomms15073 (2017).

Publisher's note: Springer Nature remains neutral with regard to jurisdictional claims in published maps and institutional affiliations.

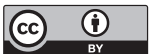

This work is licensed under a Creative Commons Attribution 4.0 International License. The images or other third party material in this article are included in the article's Creative Commons license, unless indicated otherwise in the credit line; if the material is not included under the Creative Commons license, users will need to obtain permission from the license holder to reproduce the material. To view a copy of this license, visit http://creativecommons.org/licenses/by/4.0/

(C) The Author(s) 2017 